\title{
Editorial
}

\section{Bone Microenvironment, Stem Cells, and Bone Tissue Regeneration}

\author{
$\mathrm{ZuFu} \mathrm{Lu},{ }^{1}$ Jenneke Kleine-Nulend, ${ }^{2}$ and $\mathrm{Bin}^{\mathrm{Li}^{3}}$ \\ ${ }^{1}$ Biomaterials and Tissue Engineering Research Unit, School of AMME, University of Sydney, Sydney, NSW 2006, Australia \\ ${ }^{2}$ Department of Oral Cell Biology, ACTA, University of Amsterdam and VU Amsterdam, MOVE Research Institute Amsterdam, \\ Amsterdam, Netherlands \\ ${ }^{3}$ Department of Orthopaedics, The First Affiliated Hospital, Orthopaedic Institute, Soochow University, 188 Shizi St., \\ Suzhou, Jiangsu 215006, China \\ Correspondence should be addressed to ZuFu Lu; zufu.lu@sydney.edu.au
}

Received 26 December 2016; Accepted 26 December 2016; Published 17 January 2017

Copyright (C) $2017 \mathrm{ZuFu}$ Lu et al. This is an open access article distributed under the Creative Commons Attribution License, which permits unrestricted use, distribution, and reproduction in any medium, provided the original work is properly cited.

Despite the remarkable regenerative capacity of bone, the regeneration of large bone defects and the repair of nonunion bone fractures remain a major challenge in orthopaedic surgeries. Bone is the second most commonly transplanted tissue with over 1.5 million bone graft surgeries being performed annually in the United States [1]. However, the major limitations confronted with conventional bone grafts include limited availability and donor site morbidity for autografts and the risk of pathogen transmission for allografts $[2,3]$. Given these limitations, there is a great need for developing novel and effective approaches for the regeneration of large bone defects and the repair of nonunion bone fracture.

Stem cell-based bone tissue engineering offers a promising approach for regenerating critical sized bone defects or repairing nonunion bone fracture. Understanding and recreating a signalling environment to control the differentiation of stem cells into the bone lineage would be of great importance. The components in bone microenvironment, which include a mineral phase (hydroxyapatite nanocrystals), an organic phase (composed of $90 \%$ collagen type I), a cellular phase (osteoblasts, osteoclasts, and osteocytes), and a soluble factor phase (growth factors and/or cytokines), provide a specific and balanced signalling network, which contribute to the innate bone metabolic and anabolic activities and maintain the structure and functions of the bone. Substantial efforts, therefore, have been made to mimic the bone tissue microenvironmental components for controlling the commitment of stem cells into osteogenic lineage cells for bone tissue regeneration. For example, by mimicking the bone nanostructure to engineering bone-related biomaterials, researchers have incorporated nanocrystals into biomaterials and demonstrated that they are effective in regulating various cellular functions including cell adhesion, proliferation, and differentiation $[4,5]$; in addition, mimicking the signals provided by bone cellular phase (e.g., osteoblasts) has also been shown as a feasible approach to control stem cell fate into osteogenic lineage $[5,6]$. Moreover, the cytokines and/or growth factors within bone microenvironment play a key role as well in the bone remodeling process, and mimicking their signals has been proven to be very successful in steering MSCs into bone lineage. Recently, inflammatory factors, transiently expressed by macrophages upon tissue injury, have increasingly been appreciated for their role in tissue repair and regeneration [79].

In this special issue, some cutting-edge original researches as well as review articles related to priming stem cell fate into the osteogenic lineage via mimicking the bone components (e.g., bone extracellular matrix, cells, and growth factors) were introduced and provided the readers with the updated knowledge and progression in the topic of bone microenvironment, stem cells, and bone tissue regeneration.

$\mathrm{ZuFu} \mathrm{Lu}$ Jenneke Kleine-Nulend Bin $\mathrm{Li}$ 


\section{References}

[1] D. Marsh, "Concepts of fracture union, delayed union, and nonunion," Clinical Orthopaedics and Related Research, vol. 355, pp. S22-S30, 1998.

[2] J. A. Goulet, L. E. Senunas, G. L. DeSilva, and M. L. V. H. Greenfield, "Autogenous iliac crest bone graft: complications and functional assessment," Clinical Orthopaedics and Related Research, no. 339, pp. 76-81, 1997.

[3] C. F. Lord, M. C. Gebhardt, W. W. Tomford, and H. J. Mankin, "Infection in bone allografts. Incidence, nature, and treatment," The Journal of Bone \& Joint Surgery - American Volume, vol. 70, no. 3, pp. 369-376, 1988.

[4] G. Wang, Z. Lu, X. Zhao, A. Kondyurin, and H. Zreiqat, "Ordered HAp nanoarchitecture formed on HAp-TCP bioceramics by 'nanocarving' and mineralization deposition and its potential use for guiding cell behaviors," Journal of Materials Chemistry B, vol. 1, no. 19, pp. 2455-2462, 2013.

[5] Z. Lu, S.-I. Roohani-Esfahani, G. Wang, and H. Zreiqat, "Bone biomimetic microenvironment induces osteogenic differentiation of adipose tissue-derived mesenchymal stem cells," Nanomedicine: Nanotechnology, Biology, and Medicine, vol. 8, no. 4, pp. 507-515, 2012.

[6] Z. Lu, S.-I. Roohani-Esfahani, P. C. L. Kwok, and H. Zreiqat, "Osteoblasts on rod shaped hydroxyapatite nanoparticles incorporated pcl film provide an optimal osteogenic niche for stem cell differentiation," Tissue Engineering - Part A, vol. 17, no. 11-12, pp. 1651-1661, 2011.

[7] Z. Lu, G. Wang, C. R. Dunstan et al., "Activation and promotion of adipose stem cells by tumour necrosis factor- $\alpha$ preconditioning for bone regeneration," Journal of Cellular Physiology, vol. 228, no. 8, pp. 1737-1744, 2013.

[8] G. E. Glass, J. K. Chan, A. Freidin, M. Feldmann, N. J. Horwood, and J. Nanchahal, "TNF- $\alpha$ promotes fracture repair by augmenting the recruitment and differentiation of musclederived stromal cells," Proceedings of the National Academy of Sciences of the United States of America, vol. 108, no. 4, pp. 15851590, 2011.

[9] P. M. Mountziaris, P. P. Spicer, F. K. Kasper, and A. G. Mikos, "Harnessing and modulating inflammation in strategies for bone regeneration," Tissue Engineering - Part B: Reviews, vol. 17, no. 6 , pp. 393-402, 2011. 



Submit your manuscripts at

https://www.hindawi.com
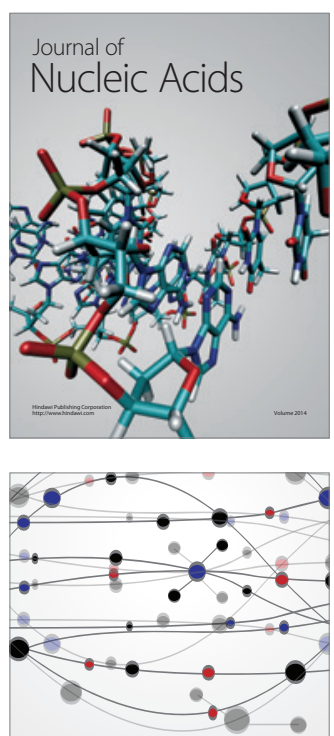

The Scientific World Journal
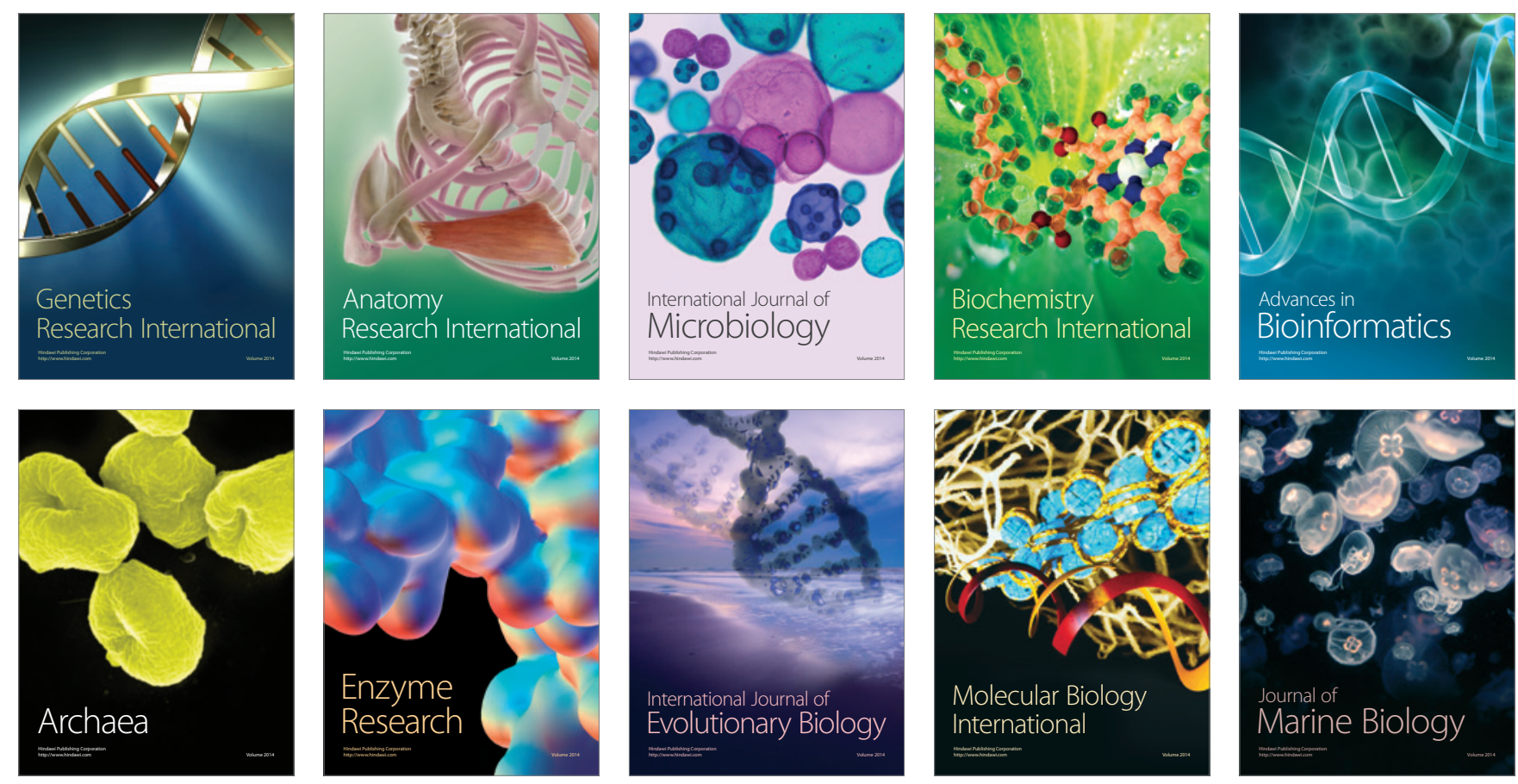